\title{
Policy discussion for sustainable integrated electricity expansion in
} South Africa

\author{
Monyei, C. G. ${ }^{1,2,4}$, Jenkins, K. ${ }^{3}$, Viriri, S. ${ }^{1}$ and Adewumi, A. O. ${ }^{1}$ \\ ${ }^{1}$ School of Mathematics, Statistics and Computer Science, University of KwaZulu-Natal, \\ Westville Campus, Private Bag X54001, Durban 4000, South Africa \\ ${ }^{2}$ Gidia Oaks Centre for Energy Research, Lagos, Nigeria \\ ${ }^{3}$ School of Environment and Technology, University of Brighton, Cockcroft Building, \\ Moulsecoomb, Brighton BN2 4GJ, United Kingdom \\ ${ }^{4}$ Corresponding author
}

\begin{abstract}
Emerging reports have shown that despite Eskom's continued investment in increasing electricity supply capacity to grid connected and off-grid households, there has been a steady decline in electricity consumption (kWh/month/individual) and household income (ZAR/month). This paper presents an integrated electricity expansion model (IEEM) for South Africa that seeks to incorporate demand side management (DSM) in providing a roadmap for improving and increasing energy (electricity) access that is sustainable, viable, ethically compliant and cost effective. In modelling IEEM, a modified genetic algorithm (MGA) would be utilized in simulating the dispatch of DSM loads (residential houses only) across the country. This paper advances traditional grid expansion planning by presenting smart policy discussions on the usefulness of IEEM in reducing associated network losses, enhancing utilization of local energy sources and minimizing expansion and plant operations costs. This paper also discusses the impact of the IEEM on the quality of life (QoL) of households and quality of service (QoS) of the utility. Electricity consumption data have been adopted from the existing literature and appropriately modified.
\end{abstract}

Keywords - integrated electricity expansion model, energy poverty, sustainability, smart policy, demand side management

\section{Highlights}

$\checkmark$ Presents an integrated electricity expansion model (IEEM) for South Africa.

$\checkmark$ Outlines the potential of IEEM to integrate DSM to minimize grid expansion.

$\checkmark$ Presents techno-economic policy discussions on potential network loss reduction.

$\checkmark$ Extends further policy discussions on poverty mitigation and REPs utilisation. 


\section{${ }_{27}$ Nomenclature}

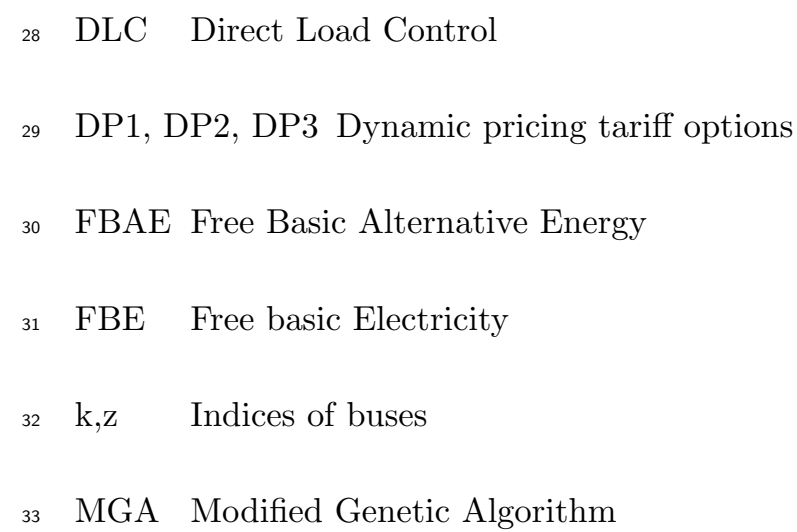

34 QoL Quality of Life

35 QoS Quality of Service

${ }_{36}$ REPs Renewable Energy Projects

37 SHS Solar Home System(s)

${ }_{38} \mathrm{~T} \quad 24$ hours duration or 96 time slots

39 t time slot of 15 minutes interval

40 TOU Time of Use pricing tariff option

\section{${ }_{41} \quad 1$ Introduction}

${ }_{42}$ According to the Transmission Development Plan (TDP) (Eskom 2015b), Eskom is expected to step up the 43 construction of additional electricity supply capacity from 2017 . The accelerated efforts by Eskom are sequel to 44 the energy crisis that has plagued South Africa since 2008; originally leading to massive blackouts, load shedding 45 and huge economic losses (Kohler 2014; Shezi 2015). While about 3,516 MW is expected to be lost from the 46 grid due to deteriorating and decommissioning of ageing power plants between 2021-2024, about 19,000 MW 47 is expected to be added to the grid capacity through new builds and capacity expansion between 2017-2024 48 (Eskom 2015b). Table 1 (Eskom 2015b) presents the planned decommissioning between 2021-2024 while Tables ${ }_{49} 2$ (Eskom 2015 b) and 3 (Eskom 2015b) present the planned supply capacity increment between 2017-2024. 50 Within, Table 2 shows the Medupi and Kusile coal-fired and Ingula pumped storage power stations as key ${ }_{51}$ developments to meet peak demand. The power plants in Table 2 all feed into the national grid.

Further, additional costs are expected to arise given the need to increase the transmission network capacity 53 and the requirement to build additional transmission and distribution stations in order to wheel power to ${ }_{54}$ homes and industry sites. It is expected that the bulk of the costs for expansion will be borne by the electricity ${ }_{55}$ consumers in form of increased electricity bills while further support will come from loans from the government 56 and commercial creditors (BusinessReport 2018). The population growth predictions shown in Table 4 (Eskom 57 $2015 b)$ present a growing trend in electricity demand forecasts. An assumed consequence of the increasing 58 population, increasing energy needs and increasing industrialization is the need for Eskom to continue to boost 59 generation capacity to always match projected demand. Yet this idea is at variance with a global trend, where 60 demand side management (DSM) initiatives are being implemented in order to reduce the need for new builds 61 and efficiently utilize existing technologies to meet current demand. This is due, largely, to the huge costs ${ }_{22}$ involved in building power stations and the long timespan between construction the synchronization of power 63 plant outputs (Ofgem 2015).

$64 \quad$ Figure 1 presents the conventional electricity expansion plan currently being exploited by Eskom. During 65 the process of executing electricity expansion, Eskom models electricity demand increases considering diverse 
factors (Gross Domestic Product (GDP), inflation, previous electricity demand growth, government policies

67 etc.) to come up with various growth patterns considering multiple variants (shown in Table 4).

\subsection{Prevailing problems associated with South Africa's electricity expansion plan}

9 The demerits of the conventional electricity expansion plan of South Africa are as follows:

- There is the possibility of a supply glut (surplus) due to over-compensation of supply capacity. Such an instance was witnessed in the 1990's and led to the mothballing of the Komati, Camden and Grootvlei power stations (Monyei and Adewumi 2017).

- There is the possibility of a supply deficit owing to either demand exceeding projections or policy inconsistencies that mitigate against the development of new builds to shore up supply capacity. Such an instance was witnessed in 2008, when supply could not meet peak demand leading to massive load shedding and blackouts (Kohler 2014; Shezi 2015).

- Low utilization of renewable energy resources. Despite considerable increase in renewable energy projects (REPs), the lack of control over end user load dispatch (flexible DSM loads) by Eskom prevents them from fully utilizing the potentials of REPs due to their stochasticity. System operation and planning is thus done using base load stations (coal and nuclear) whose capacities and performances can be evaluated exactly.

- The loss of loads and blackouts remain a possibility. In instances of peak demand, the inability of Eskom to quickly dispatch end user loads without financial penalties means the possibility of load shedding becomes high.

- Electricity billing could be excessive. According to Eskom (2017b), between 2008 and 2013, electricity price cumulatively rose by about $114 \%$ which was at variance with declining electricity prices prior to 2008/09. The sharp increase in electricity price (which was to enable Eskom raise future revenue to cover for new builds) was met with increasing public resistance (Eskom 2017b). Eskom has thus consistently argued for further increases in electricity prices to enable it to bridge its revenue shortfall (R35 billion in 2014/15).

\subsection{Major contributions of this research}

The aim of this paper is to study and show the impact of an electricity expansion model (that integrates all aspects of the electricity grid) on peak demand reduction, expansion costs reduction, capacity utilization maximization, maximization of earnings (for the supply side), minimization of electricity costs (consumption/utilization side) and network loss reduction. This is consequent on the fact that in addressing the issues associated with the conventional system of electricity expansion planning in South Africa, there is the need for an electricity expansion plan that is capable of: 
- Isolating consumers from extreme price fluctuation due to the utility's billing system that attempts to recoup investments on new builds.

- Utilizing REPs effectively.Rather than expending huge sums building large-scale storage facilities for wind and solar projects, end user loads could be dispatched during times of wind/solar availability. While we acknowledge the role of battery energy storage in stabilizing the electric grid and enabling the integration of REPs (Hu et al. 2017), we however draw caution from DiOrio et al. (2015) who offer that it is necessary to evaluate the utility rate structure, and determine whether the addition of battery storage can be leveraged to reduce costs enough to justify the upfront capital expenditure and replacement costs. This is important in ensuring that consumers do not become unnecessarily over-burdened with huge electricity bills.

- Efficiently utilizing installed supply capacity. With adequate knowledge of demand schedules and operational control of a fraction of end users loads, the utility is able to optimally dispatch generation sources and allocate end user loads such that dispatched supply capacity is efficiently utilized. This is necessary to prevent energy wastage, reduce emissions and operations losses.

- Minimizing network losses ${ }^{1}$. With advanced knowledge of demand growth profiles across the provinces, it becomes possible to evaluate the associated costs (economic, losses) and benefits of situating a generation source closer to a demand hub ${ }^{2}$ or extending the transmission network from the generation hub ${ }^{3}$ to the demand hub. While it might be economical to locate power plants close to primary fuel sources, there is the possibility of incurring high economic costs and he network losses through evacuating power from the generation site to load centres. Balancing the location of generation sources to minimize economic costs and network losses becomes important.

- Minimizing expansion. The ability to predict demand growth and evaluate operational DSM (by which we mean flexible loads whose operation hours can be influenced externally) capacity provides the utility company with an avenue to explore varied energy supply mix options, including REPs. This may minimize the utility's expansion of supply capacity, inherently improving efficiency and reducing expansion costs.

Figure 2 presents the proposed integrated electricity expansion model (IEEM). In differing from Figure 1,

Figure 2 operationalizes DSM. By this, we mean that it makes DSM load hours of operation flexible. In Figure 1, DSM initiatives being adopted by Eskom consist of energy efficiency demand side management (EEDSM). In 2008, Eskom began a campaign to exchange incandescent bulbs in homes for more energy efficient compact fluorescent lamps (CFLs) with about 65 million of such energy efficient CFLs installed in South African homes to date. The result has been considerable energy savings and reduced electricity bills, job creation and a culture of greater energy efficiency among South Africans. It is estimated that about 11.8 TWh of DSM programs are

\footnotetext{
${ }^{1}$ According to Eskom (2015a), total technical energy losses for the 2014/15 financial year was estimated at 8.79\%. While transmission losses (estimated at 2.53\%) are mainly associated with power evacuation and increase with distance, distribution losses (estimated at 6.78\%) are influenced by factors such as network design, network topology, load distribution and network operations.

${ }^{2}$ We define a demand hub to be a cluster of provinces with cumulative demand exceeding $15 \%$ of the total demand for South Africa.

${ }^{3}$ By generation hub we mean a cluster of power plants with generation capacity exceeding $30 \%$ of total generation capacity of South Africa. An example of such is the Mpumalanga Power Pool (MPP).
} 
currently in place in South Africa with expected cumulative savings of $466 \mathrm{MW}$ by 2017/2018 from the additional the projected savings expected from such measures, their impact is passive due to the fact that the utility has no influence over the utilization time of EEDSM initiatives like CFLs distribution in South Africa. Figure 2 advances Figure 1 by incorporating price based DSM with specific loads either being controlled directly by the utility (direct load control, DLC) or by the home owners (within a flexible window).

\section{The integrated electricity expansion model (IEEM) and related} works

As shown in Figure 2, in predicting demand growth, the growth of flexible customers ${ }^{4}$ is also predicted across the provinces. This is necessary as it helps in determining the minimum expansion needed (rather than the conventional expansion model shown in Figure 1 that aims for maximum expansion units).

A review of related literature for South Africa shows that only Monyei and Adewumi (2017) have been able to quantitatively illustrate growing energy poverty in South Africa as well as providing initial evidences of the benefits of operationalizing DSM for an isolated case. Other related works on the electricity sector in South Africa have centred around associated statistics and policy, for example Blommestein and Daim (2013)who carried out the evaluation of consumers decision making processes around energy efficient devices using a hierarchical decision model (HDM) to determine if there was a sync between consumers technology focus and current efficiency initiatives; Amusa et al. (2009) who applied bounds testing approach to co integration with an autoregressive distributed lag framework to examine South Africa's electricity demand during the period 1960-2007 and Inglesi (2010) who forecast (using the Eagle-Granger methodology for co-integration and error correction models) the electricity demand of South Africa up to 2030. Similarly, DSM studies have been carried out by Clark (2000), who investigate the factors inhibiting municipalities from investing in DSM initiatives; Lombard et al. (1999) where a program for thermal efficiency in the South African residential sector was proposed and Rankin and Rousseau (2008) where the authors described how an improved inline water heating concept was capable of achieving peak load reduction without availability compromise within the specified operating time. Furthermore, other researchers have extended studies to pricing and its effect on electricity demand. For example, the effect of pricing policy on aggregate electricity demand and the magnitude of demand change/response to a variation in pricing policy between 1960-2007 for South Africa was studied in Amusa et al. (2009), while Inglesi-Lotz (2011) applied the Kalman filter in estimating the price elasticity of electricity in South Africa between 1980-2005.

\footnotetext{
${ }^{4}$ We define flexible customers for this paper to be households with grid access and who have agreed to participate in DSM initiatives by either leaving the dispatch of selected loads to the utility within a flexible window or strict flexible window. By flexible window, we mean 24-hours window and by strictly flexible window, we mean a 2-hour window. Selected loads for this paper are cloth washers, cloth dryers and dishwashers. The incentive for participation is a reduction in electricity bills for the participating loads.
} 


\subsection{Motivation for IEEM}

The 1990's mothballing of power production plants (see Monyei and Adewumi 2017) as well as the subsequent supply deficit in 2008 that precipitated the blackouts and load shedding that characterized the electricity network of South Africa between 2008-2015, necessitates a more proactive model that is sustainable and flexible. Furthermore, growing/expanding grid access has not directly translated to increasing electricity consumption (kWh/capita). Monyei and Adewumi (2017) illustrate this by investigating declining electricity per capita, as do STATSSA (2017), who illustrated an increase in South African poverty rates (estimated to be about 55.5\%). It can thus be inferred that increasing poverty will directly result in decreasing disposable income and increasing energy poverty (since households would spend more of their disposable income purchasing lesser electricity units due to increasing electricity tariffs). In addition, Monyei and Adewumi (2017) offer that the estimated addition to the grid capacity between $2017-2024$ is over 500\% in energy terms. This thus implies that Eskom stands at a higher risk of incurring further revenue shortfall due to increasing operational losses (owing to underutilization of installed capacity, increasing operations and maintenance costs and reduced revenue owing to decreased electricity units purchases). IEEM is thus important in obviating the need for maximum demand sizing in grid expansion by introducing flexible customers and efficiently utilizing REPs. Further, this paper advances the discuss in Monyei and Adewumi (2017) beyond an isolated case by computing DSM potentials and evaluating its impact (in terms of cost and expansion) for South Africa and making policy recommendations.

\section{The IEEM description and application}

In attempting to model DSM for South Africa and provide policy recommendations as regards electricity expansion, network losses, REPs utilization and electricity tariffs, we first describe South Africa's main electricity company and the electricity network model employed in this paper.

\subsection{A brief description on Eskom}

The major electricity provider in South Africa is Eskom, which generates over 95\% of the total electricity consumed in South Africa and about 45\% of electricity produced in Africa. In addition to electricity generation, Eskom owns the majority of the transmission network in South Africa with an average yearly production of about $200000 \mathrm{GWh}$. Eskom generates and sells electricity to municipalities (42.7\%), industries (22.3\%), mines (14.4\%), commercial and agricultural based companies (7\%), rail companies $(1.4 \%)$ and exports about $5.6 \%$ of its electricity. Their major production sources for electricity include coal (83\%), nuclear (5\%) and imports (4\%). Imports are from the Southern African Power Pool (SAPP) which is an inter-connected regional transmission network of the Southern African Development Community (SADC) (Monyei and Adewumi 2017). 


\subsection{Description of model electricity network for South Africa}

Given $P^{t}(\mathrm{MW}), B L^{t}(\mathrm{MW})$ and $D S M^{t}(\mathrm{MW})$,

$$
B L^{t}+D S M^{t}=P^{t}
$$

The objective function $P_{I E E M}^{t}$ is defined as

$$
P_{I E E M}^{t}=\min \left(P^{t}\right)
$$

Given $C^{\exp }(\mathrm{ZAR} / \mathrm{MW})$ to be the cost of adding an additional MW to the national grid, then the objective function $C_{I E E M}^{e x p}$ is defined as

$$
C_{I E E M}^{e x p}=\min \left(C^{e x p}\right)
$$

\subsubsection{Capacity utilization maximization}

Given $U t i l^{t}(\%)$ to be the average utilization of power plants across South Africa, the objective function $U t i l_{I E E M}^{t}$ is defined as

$$
U t i l_{I E E M}^{t}=\max \left(U t i l^{t}\right)
$$

\footnotetext{
${ }^{5}$ Major transmission network of South Africa consists of 765-kV, 533-kV, 400-kV, 275-kV, 220-kV and 132-KV lines.
} 


\subsubsection{Revenue maximization - supply side}

Given $\operatorname{Supp}^{T}$ (ZAR/day) to be the total daily revenue earned by the supplier from electricity sold, the objective function $\operatorname{Supp}_{I E E M}^{T}$ is defined as

$$
\operatorname{Supp} T_{I E E M}^{T}=\max \left(\operatorname{Supp}^{T}\right)
$$

where $\operatorname{Supp}^{T}=\sum_{t=1}^{t=96}\left(\operatorname{Supp}^{t}\right)$

\subsubsection{Electricity cost minimization - consumer side}

Given $H^{\exp }$ (ZAR/day) to be the daily electricity cost for a house participating in DSM, the objective function $H_{I E E M}^{\exp }$ is defined as

$$
H_{I E E M}^{e x p}=\min \left(H^{e x p}\right)
$$

\subsubsection{Network loss minimization - transmission only}

Given $\operatorname{Loss}^{T}$ (MW) to be the daily transmission losses for the electricity network, the objective function $\operatorname{Loss}_{I E E M}^{T}$ is defined as

$$
\operatorname{Loss}_{I E E M}^{T}=\min (\text { Loss })
$$

210 where $\operatorname{Loss}^{T}=\sum_{t=1}^{t=96}\left(\operatorname{Loss}^{t}\right)$

\section{${ }_{211} \quad$ 3.3.7 Operations cost minimization}

Given $O P^{T}$ (ZAR/day) to be the daily operations cost in generating and distributing electricity by the utility, the objective function $O P_{I E E M}^{T}$ is defined as

$$
O P_{I E E M}^{T}=\min \left(O P^{T}\right)
$$

Subject to

$$
O P^{T}=F^{T}+E^{T}+M t^{T}
$$

\subsection{Solving the network model}

The Gauss-Seidel model has been chosen for attempting to solve the resulting load flow problem from Figure 3. Its choice is basically due to familiarity and ease of programming and speed since Newton-Raphson takes longer because of the need to recalculate the Jacobian (Gilbert et al. 1998). Applying Kirchoff's current law 
given the bus admittance matrix yields equation 10 .

$$
I=Y_{b u s} V
$$

The $k^{t h}$ nodal current of $\mathrm{N}$ nodes (BUSES) is obtained to be $I_{k}=\sum_{z=1}^{N}\left(Y_{k z} V_{z}\right)$ which can be resolved to give (11).

$$
I_{k}=Y_{k k} V_{k}+\sum_{z=1}^{N}\left(Y_{k z} V_{z}\right)
$$

Re-arranging (11) to obtain $V_{k}$ is shown in (12).

$$
V_{k}=\frac{I_{k}}{V_{k k}}-\frac{1}{Y_{k k}} \sum_{z=1}^{N}\left(Y_{k z} V_{z}\right)
$$

if $S_{k}=P_{k}-j Q_{k}$ then (13) is obtained.

$$
V_{k}^{t^{\prime}+1}=\frac{1}{Y_{k k}}\left[\frac{P_{k}-j Q_{k}}{\left(V_{k}^{t^{\prime}}\right)^{*}}-\sum_{z=1}^{N}\left(Y_{k z} V_{z}^{t^{\prime}}\right)\right]
$$

231

Where $I_{k}$ is current, $V_{k} / V_{z}$ is voltage and $Y_{k k} / Y_{k z}$ is bus admittance matrix. The modelling of the Gauss-Seidel operation is constrained to ensure that convergence is only possible within allowed bus voltage limits. Similarly, $S_{k}, P_{k}$ and $Q_{k}$ are the apparent, real and reactive power (all in per unit) at bus k.

\subsection{Assumptions for network}

The network model shown in Figure 3 is assumed, within realistic approximations, to present valid values for the South African electricity network. The following have been assumed in simplifying the electricity network for South Africa:

- Only base load generation stations (coal and nuclear) have been used in the simulation.

- All base load generation stations within a province have been merged to form a pool (PP1-PP5).

- The load within a province have been merged to also form a pool (LP1-LP9).

- Random lengths have been assigned to the transmission lines to enable the computation of line losses due to variation in situating generation plants. For this paper, the length of the transmission line is immaterial since we are solely interested in the variation (percentage increase/decrease) of network transmission losses due to variations in the location of power generation plants.

- The transmission lines are all assumed to have infinite ampacity limits.

- Power imports have been included in PP1 (from Botswana) and PP3 (from Mozambique). 


\section{Scenario modelling}

Three scenarios (Scenarios 1, 2 and 3) are modelled and discussed with respect to Section 3.3.1 to Section 3.3.7. For each Scenario being modelled, three cases are considered. The adoption of varying locations for power station placement is to explore the effect of power plant location on parameters such as network loss, utilization, reactive power compensation, voltage profile etc. The scenario modelling thus assists in determining the optimal location for locating power plants that will achieve an optimal system configuration at the minimum cost. Furthermore, the variation in the DSM profiles is to evaluate the extent to which flexibility in DLC affects peak demand, supply capacity utilization and other associated costs.

- Case 1: Here, households participating in DSM determine when participating DSM loads are to be dispatched within a time-frame ${ }^{6}$. For this case, the time-frame is 05:00-08:00 and 17:00-22:00. It is also assumed that the dispatch of DSM loads (DSM-potential for each province is shown in Table 5) under this case follows the natural and unconstrained usage pattern of participating households.

- Case 2: Under this case, the participating DSM loads (DSM-potential shown in Table 7) are dispatched by the utility across the day. The time-frame is from 00:00 - 00:00 (next day). The incentive for participation is the reduction of electricity bills for the participating households. This case also offers the utility the most flexibility in optimizing the dispatch of generation plants to reduce its operation costs and improve capacity utilization. The DSM loads are under direct load control (DLC) by the utility.

- Case 3: Under this case, the utility dispatches participating households DSM loads within the time-frame 05:00-08:00 and 17:00-22:00 with the possibility of exceeding 08:00. DSM loads (DSM-potential shown in Table 5) are under DLC in this case. In differing from Case 1, Case 3 incorporates DLC for the dispatch of the DSM loads. Similarly, Case 3 differs from Case 2 by adopting a more constrained time-frame (similar to Case 1). Case 3 also offers households reduction in electricity bills and reduced operation costs for the utility.

Figure 4 depicts the dispatch time profile for participating DSM loads. It is seen from Figure 4 that the time-frame is denoted by $w_{i}$ where $w_{i}$ is 2 -hours for Cases 1 and $3^{7}$ and 24 -hours for Case 2 . Also, $t_{i, j}^{\text {start }}$ is the earliest start time for DSM load $j$ in house $i$ and is 05:00 for Cases 1 and 3 and 00:00 for Case 2. $t_{i, j}^{\prime}$ is the latest time a participating DSM load can be dispatched based on its hours of operation $\left(t_{i, j}^{\text {duration }}\right), t_{i, j}^{\text {dispatch }}$ is the time of actual dispatch of the DSM load $j, t_{i, j}^{\text {stop }}$ is the latest stop time for a dispatched DSM load $j$ while $t_{i, j}^{f i n a l}$ is the actual stop time for a dispatched DSM load $j$. Table 6 presents the description of the participating DSM loads including their duration of dispatch and power rating while Figure 5 presents the daily base load profile for all provinces. The justification for the choice of the participating DSM loads is explicitly discussed in Monyei and Adewumi (2017). In modelling the different Cases (1, 2 and 3), the incorporated MGA (Monyei and Adewumi 2017) aims at minimizing the peak demand (MW) for the DSM loads (irrespective of the base loads). Figure 6 presents the cumulative DSM profile for all Cases and provinces and is utilized for all Scenarios.

\footnotetext{
${ }^{6} \mathrm{~A}$ time-frame for this paper is the period within which DSM loads are to be dispatched i.e. from $t_{i, j}^{\text {start }}$ to $t_{i, j}^{\text {stop }}$.

${ }^{7}$ This would not always hold for Case 3 due to the possibility of $t_{i, j}^{\text {stop }}$ exceeding the 2-hours limit for some households.
} 


\section{$4.1 \quad$ Scenario 1}

In Scenario 1, we model the electricity network shown in Figure 3 with DSM and base load considerations as shown in Figures 6 and 5 respectively and the normal placement of base load power generation plants as shown in Table 7. This scenario provides a baseline for comparison purposes with all other scenarios. Table 8 provides further explanation to Table 7. BUS 2 is assumed to be the slack bus for this case while other generating plants are dispatched at $70 \%$ capacity utilization.

\subsection{Scenario 2}

In Scenario 2, we model the same electricity network as used in Scenario 1 (i.e. Figure 3) utilizing same DSM and base load profiles (shown in Figures 6 and 5 respectively) but with power plant distribution as shown in Table 7 (as modified). The placement of the additional power plants for this scenario is by inspection (randomly) and does not follow any scientific method. Similar to Scenario 1, BUS 2 is taken to be slack bus while other generation power stations are dispatched at $70 \%$ capacity utilization.

\subsection{Scenario 3}

Scenario 3 is similar to Scenario 2 but with an additional power plant as described in Table 7 . The additional plant added to the indicated bus is assumed to be a base load power generation plant (typically coal or nuclear). However, the plant could also be a combination of other sources - natural gas, REPs etc. BUS 2 is taken to be the slack bus with other generation power plants dispatched at $70 \%$ capacity utilization.

\subsection{Price modelling}

Four varying pricing models are utilized in order to show the robustness of IEEM and aid policy discussions. The time of use (TOU) and 3 dynamic pricing schemes (DP1, DP2 and DP3) as shown in Figure 7, are adopted in evaluating electricity cost for the DSM loads only in all Cases. Irrespective of the scenario modelling $(1,2$ or 3) adopted, the cost of the DSM loads for all cases remains the same for the scenarios. The Eskom TOU pricing scheme adopted is for a household whose monthly electricity consumption is an average of $600 \mathrm{kWh}$. The cost for off-peak periods is about $Z A R 1.25 / \mathrm{kWh}$ and is exclusive of the peak period prices. For the purpose of this research, $20 \%$ has been added to the spot price during off-peak periods to generate the peak period (6am-8am and $6 \mathrm{pm}-9 \mathrm{pm})$ TOU price. Weekdays and weekend peak periods have been assumed to be similar. Similarly, for the dynamic pricing schemes adopted, the computation of the dynamic price $D P^{t}$ (where DP could be DP1, DP2 or DP3) follows the time of use (TOU) pricing being used by Eskom. Given $F P^{t}$ as the TOU pricing electricity spot price, then $\frac{1}{96} \sum_{t=1}^{t=96}\left(D P^{t}\right)=\overline{F P^{t}}$ (Monyei and Adewumi 2017). 


\section{Results and discussion}

Table 9 presents the associated statistics for the DSM loads only. It is observed from Table 9 that irrespective of the scenario, Case 2 has the lowest build size of $173.48 \mathrm{MW}$ while Case 1 has the highest build size of 495.01 MW. The selection of the maximum build size is based on the highest power demand (based on DSM load allocation by MGA) across the day. Also presented in Table 9 is the cost of electricity (DSM loads only) across the cases. Using TOU cost as the baseline cost, it is seen that Cases 1 and 3 offer competitive prices in terms of cost reduction for the participating households (utilizing DP1 and DP2). For example, in Case 1, DP1 offers a $25.41 \%$ cumulative reduction in combined DSM load electricity cost while DP2 offers a $13.41 \%$ cumulative electricity cost reduction for all participating households. Similarly, for Case 3, DP1 offers $18 \%$ cumulative reduction in electricity cost with DP2 offering cumulative electricity cost reduction of $8.67 \%$. The cumulative reduction in electricity costs (for Case 1 using DP1) translates to $3.26 \mathrm{kWh}$ daily savings per household (based on $1.25 \mathrm{ZAR} / \mathrm{kWh}$ ). This could either be used in extending electricity usage or other activities that could improve the quality of life (QoL) of households.

Based on Eskom (2017b) and Eskom (2015b), the average cost of building supply capacity for 2016/17 is estimated at ZAR 9.39 million/MW. The implication of this is that excluding operations and other associated costs, the build cost for Case 3 (363.84 MW) can be recovered (from DSM loads only) in about 194 days using DP1 and about 174 days using DP2. While Case 2 offers a very competitive value in terms of expansion cost reduction, its offer of competitive pricing for participating households is almost negligible. Table 10 presents the daily cumulative losses across the network (Figure 3) for all cases and scenarios. Across all cases, it is observed that losses reduced by $2.5 \%$ between Scenario 1 and Scenario 2 for Cases 1 and 3 (2.65\% for Case 2) and $0.35 \%$ between Scenario 2 and Scenario 3 for all cases.

It is observed that the placement of arbitrary generation plants in BUS 8 (Scenario 2) and BUSES 3 and 8 (Scenario 3) results in a reduction in transmission losses (shown in Table 10). The implication of this is that less pressure (in terms of extra demand) is put on the Mpumalanga Power Pool (MPP). This frees up capacity at MPP for maintenance and also reduces capacity expansion at MPP due to utilization of the local generation power stations (or local REPs).

Figure 8 presents the effect of the additional power plants (Scenarios 2 and 3) on the ampacity of the transmission lines. It is observed from Figure 8 that there is a significant drop in current flowing through lines $1,8,10,13,14$ and 15 with significant increase in line current observed in lines 2, 3, 4, 5, 6 and 12 . Current through lines 9 and 11 remained averagely unaffected across the scenarios and cases. The utility of this result is in determining transmission lines that need to be upgraded or supported to enable evacuation of power from one bus to another.

The variation in BUS voltage across the scenarios is shown in Figure 9. It is observed from Figure 9 that bus voltage profile is averagely unaffected for most buses with significant drop in bus voltage observed for BUSES 3, 7 and 9. Also, while no bus voltage exceeds the upper bus limit of 1.113 per unit, BUSES 2, 3, 6, 7 and 8 fall below the lower limit 1.007 per unit for all scenarios and cases (base voltage is 1.06 per unit). 
The utilization of capacity build for participating DSM loads is further shown in Table 9 to be $33.34 \%$ for Case 1, 95.14\% for Case 2 and $45.36 \%$ for Case 3 (irrespective of scenario). The high utilization observed for Case 2 as a result of DLC compromises on electricity bill reduction for participating households. Under Case 2, DP1, DP2 and DP3 tariffs translate to about ZAR 10.62 (8.50 kWh/month), ZAR 8.75 (7.00 kWh/month) and ZAR 12.74 (10.19 kWh/month) monthly electricity bill reduction/energy savings for participating households. In offering higher utilization of capacity build and guaranteeing maximum revenue accrual to the utility (based on the similarity in earnings irrespective of the tariff method adopted), Case 2 compromises on significant electricity bill reduction for participating households. Cases 1 and 3, which both compromise on utilization of capacity build and maximum returns for the utility (for DP1 and DP2), guarantee participating households significant monthly electricity bill reduction of $16.3 \%$ and $8.6 \%$ (for Case 1) and $11.3 \%$ and $5.4 \%$ for (Case 3 ). IEEM thus provides an interactive platform that enables Eskom investigate the impact of DSM and varying load control options (Cases 1, 2 and 3) on its capacity expansion and revenue accrual.

\section{${ }_{343} 6$ Policy discussions}

In discussing further the results obtained, policy discussions on IEEM would focus on its network loss reduction capabilities, expansion cost minimization potentials, electricity cost reduction potentials, poverty mitigation, technical and economic evaluation potentials for electricity network expansion. Here, we discuss each in turn.

\subsection{Policy discussion on network loss reduction}

According to Eskom (2017b), transmission loss is about 7.5\% of total power produced which results from the long distance between the major power pool (BUS 2) and load points LP3, LP4, LP8 and LP9. Results obtained show that the majority of losses occur on lines 1, 3, 11 and 15 . This is as a result of the unavailability of local base power stations or alternative power sources at BUSES 3, 4, 8 and 9. However, the introduction of fictitious power stations at BUSES 3 and 8 lead to significant current drop in lines 1, 14 and 15. Since losses are directly related to current flow, this means that reducing the current flowing through a transmission line would lead to a corresponding decrease in the losses through the respective line. IEEM this offers Eskom a model to assess the cost of citing power stations at local points of consumption (construction, fuel, maintenance, water etc.) and savings/benefits (loss reduction, enhanced grid security and utilization of local REPs). Furthermore, a reduction in network losses translates to longer operational life of the transmission line, reduced costs for transmission network expansion and network security.

\subsection{Policy discussion on expansion costs reduction}

The transmission development plan (TDP) (Eskom 2015b) outlines the intent to expand supply capacity by over $500 \%$ in energy demands in response to anticipated demand growth between 2017-2024 (Monyei and Adewumi 2017). With a moderate estimated cost of ZAR 9.39 million/MW, Eskom would need to hike electricity prices excessively to recoup their investments. IEEM provides an alternative. By incorporating DSM at 10\% 
participation of electrified households in South Africa, IEEM reduces capacity expansion from $495.01 \mathrm{MW}$ to 173.48 MW (Case 1 to Case 2) and 495.01 MW to 363.84 MW (Case 1 to Case 3). This translates to savings of over ZAR 3 billion for Case 1 to Case 2 and over ZAR 1.2 billion for Case 1 to Case 3. This thus implies that more savings could be achieved with the incorporation of further households and loads (heating, cooling, lighting, industrial etc.).

\subsection{Policy discussion on electricity cost reduction}

IEEM offers Eskom the opportunity of incentivizing households through the adoption of pricing tariffs that reduce the electricity bill of participating households DSM loads. For example in Table 9, under Case 1, DP1 offers about ZAR 122/month/household savings which is about a $16 \%$ reduction in a typical household's monthly electricity bill (households consuming $600 \mathrm{kWh} /$ month and under). In energy costs, this translates to about 98 $\mathrm{kWh} /$ month/household (at ZAR 1.25/kWh).

\subsection{Policy discussion on poverty mitigation}

According to STATSSA (2017) and Monyei et al. (2018b), over 50\% of South Africa's households are poor. It can be inferred that the declining electricity consumption in households (Monyei and Adewumi 2017) despite increasing investments in electricity capacity expansion has been exacerbated by the increasing cost of electricity. Households are thus forced to purchase less electricity units due to higher tariffs leading to energy poverty. IEEM provides policy makers an avenue to improve households QoL and precipitate economic growth through the adoption of flexible pricing tariffs (DP1, DP2 and DP3) and operational DSM. From Table 9, under Case 1, households are able to reduce monthly electricity bill by up to $16 \%$ which translates to energy savings of about $98 \mathrm{kWh} / \mathrm{month} /$ household. The savings can be used to either extend operation time of electrical appliances that can contribute to households QoL (lighting, entertainment, heating, cooking) or engage in other activities that are also capable of improving households QoL.

\subsection{Policy discussion on capacity utilization}

The impact of varying load control strategies - constrained user defined (Case 1), DLC (Case 2) and constrained DLC (Case 3) has been presented in Table 9. IEEM enables Eskom investigate the potential impact varying control strategies in terms of load dispatch could have on plant utilization, revenue accrual and electricity bill reduction. As observed from Table 9, DLC (Case 2) offers Eskom more operational control of the electricity network (generation, transmission and end-use dispatch time). Also, despite Cases 1 and 3 offering reduced capacity utilization compared to Case 2, Eskom is able to dispatch base loads during the periods of low utilization by reducing generation capacity for base loads during the periods of low utilization. 


\subsection{Policy discussion on rural electrification expansion}

\footnotetext{
${ }^{8}$ By rural peripheralisation, we extend its meaning beyond Sovacool et al. (2017) to mean discrimination in the quality of electricity households can access based on their proximity to the grid.
} 


\subsection{Policy discussion on network security}

According to eePublishers (2014), South Africa's electricity grid is expected to be N-1 compliant by 2022. This means that the loss of any major transmission line or generating station is capable of precipitating grid collapse. Furthermore, in the event of a major network fault, the unavailability of flexible customers/loads implies that deliberately disconnecting consumers leads to economic losses and impacts negatively on their QoL. IEEM, through the incorporation of DSM, provides Eskom with leeway (operational freedom) in balancing the grid without economic repercussions. Furthermore, IEEM provides Eskom with an advanced simulation tool that can be used in simulating extremities on the grid to evaluate the extent of grid security and response during faults.

\subsection{Policy discussion on pricing}

Eskom's pricing is mostly influenced by its projected capital expenditure on maintenance, new builds, overhead, operations, insurance and other associated running costs. According to Eskom (2017b), there was a revenue shortfall of about R35 billion for 2014/15 due to low tariff. However, while Eskom aims at maximizing revenue accrual through higher tariffs, the resulting increase in tariff is capable of precipitating poverty. Households are thus forced to spend a higher percentage of their income on reduced electricity units, leading to energy poverty. This, in turn, can lead to reduced electricity consumption (as established in Monyei and Adewumi 2017) and lower utilization of supply capacity, inherently leading to higher operations cost and increased operational losses. According to Zhang (2012), investment in energy efficiency (especially for households and industries) can be improved upon by mandatory targets and electricity prices. Appropriate pricing regimes are thus needed that are capable of billing households based on their income level and rate/level of participation in DSM activities and also encouraging energy efficiency investments. IEEM thus offers a platform for the exploration of the effect of various pricing schemes on revenue accrual (for the utility) and peak demand reduction.

\section{Conclusion}

This paper has presented IEEM and studied its impact on both Eskom and consumers. This paper has shown that IEEM advances traditional generation expansion planning (GEP) beyond conventional demand growth expansion and generation capacity estimation. IEEM through the incorporation of DSM, provides Eskom with varied options in terms of expansion planning (expansion capacity, possible revenue accrual and associated network losses) which helps in better informing decisions on the type of generation capacity to build and location. Considering the dispersed REPs across South Africa, IEEM has provided a platform that enables Eskom utilize their capacity in dispatching flexible loads. Furthermore, IEEM has also shown its capability in mitigating poverty through electricity bill reduction for participating households. With up to $16 \%$ reduction in electricity bill for a typical household, more units could either be purchased by households to extend usage of electrical appliances or for other activities that are capable of improving their QoL. 
In mitigating rural peripheralisation, IEEM provides enormous savings for Eskom through reduction in expansion costs (due to the incorporation of DSM) which can be used in financing and strengthening the FBE and FBAE. Considering the huge disparity in the quality of energy access between grid connected poor home and off-grid poor homes, extra revenue saved from minimized capacity expansion can be used in improving offgrid electrification projects. Such improvement in electricity access for rural and off-grid communities is capable of stimulating economic growth. This is in line with Azimoh et al. (2017), who offer that while electrification cannot solve the entirety of the developmental problems plaguing rural households, households cannot access development assistance opportunities without having access to electricity.

Considering previous cases of power plants mothballing (due to excess supply capacity) and subsequent load shedding due to demand exceeding supply capacity, IEEM helps in preventing this by ensuring that despite reduced reserve margins, the availability of flexible customers/loads provides it (the utility) with allowance to always balance the grid and optimally utilize available supply capacity to dispatch demand. With increased operational control over electricity generation, transmission and utilization time, Eskom is able to ensure grid security and stability. This becomes necessary as the participation of REPs in the grid increases. Due to the stochasticity in the availability of REPs, the presence of flexible loads aids Eskom in maximizing REPs output whenever available without negatively impacting on the QoL of households.

With deliberate action plans being undertaken by countries to reduce carbon emissions, IEEM provides Eskom with a platform for evaluating resulting expansion options based on pre-determined emissions cap. Based on estimated number of households participating in DSM operations and capped emissions, IEEM provides Eskom with possible expansion options which help in formulating decisions/policy on billing strategy to be adopted. This is important to Eskom, especially when applying for tariff increase approval from NERSA. IEEM thus offers an interactive platform for expansion planning beyond traditional generation expansion models by aiding NERSA in appropriately billing Eskom for emissions without adversely affecting consumers (who often bear such penalties).

IEEM can also be useful to the regulator (NERSA) as it enables them to view the impact of its policies (carbon tax, tariff increase approval) on Eskom (revenue accrual, operations cost) and consumers (electricity cost, QoL, poverty). This thus helps NERSA in formulating streamlined regulatory frameworks (SRFs) ${ }^{9}$ that are capable of stimulating economic growth and mitigating poverty.

\section{Policy implementation and its challenges}


(in real/near-real time) with participating DSM loads. Furthermore, the municipalities make profit from sale of electricity to households [who make up over $40 \%$ of municipalities customers (Eskom 2017b)]. The problem of price harmonization becomes a problem since sale of electricity is a major source of income to the municipalities. Lastly, security concerns do exist in households to smart meters owing to fears of intrusion and subtle monitoring of consumption pattern which the utility could use in developing billing strategies that would penalize them higher than the TOU pricing scheme (Sovacool et al. 2017).

\section{IEEM limitation and future research}

While IEEM has explored the impact of residential DSM on capacity expansion, there is the need to incorporate industrial and commercial consumers to evaluate the effect of flexible industrial loads (heating, ventilation and cooling, HVAC) and flexible industrial processes on capacity expansion, network losses, revenue accrual and electricity costs reduction. Furthermore, IEEM has not considered the role of social institutional processes in facilitating a smart and just electricity expansion. Future work would seek to integrate socio-technical transition processes in improving IEEM.

\section{Acknowledgements}

The first author acknowledges the financial assistance of the National Research Foundation (NRF) and The World Academy of Sciences (TWAS) through the DST-NRF-TWAS doctoral fellowship (105474) towards this research. Opinions expressed and conclusions arrived at, are those of the authors and are not necessarily to be attributed to the NRF.

\section{References}

[1] Eskom. Transmission Development Plan 2016-2025. [Online] Accessed: 2017-05-18. 2015. URL: http: //www.eskom.co.za/Whatweredoing/TransmissionDevelopmentPlan/Documents/TransDevPlan20162025Brochure.pdf.

[2] Marcel Kohler. "Differential electricity pricing and energy efficiency in South Africa". In: Energy 64 (2014), pp. 524-532. DOI: 10.1016/j .energy . 2013.11.047. URL: http://linkinghub.elsevier.com/ retrieve/pii/S0360544213010177.

[3] Lungelo Shezi. Loadshedding to run from 8am to 10pm today. [online] Accessed: 2017-05-01. 2015. URL: http://www.htxt.co.za/2015/05/21/loadshedding-to-run-from-8am-to-10pm-today/.

[4] BusinessReport. PIC will bail out Eskom with a R5 billion loan. [Online] Accessed: 2018-05-01. 2018. URL: https : / /www . iol . co . za/business - report/energy / pic-will-bail - out - eskom - with-a-r5billion-loan-13113950. 
[5] Ofgem. Making the electricity system more flexible and delivering the benefits for consumers. Accessed: 2017-04-20. London., 2015. URL: https ://www .ofgem.gov .uk/ofgem-publications/96959/flexibilitypositionpa pdf.

[6] C.G. Monyei and A.O. Adewumi. "Demand Side Management potentials for mitigating energy poverty in South Africa". In: Energy Policy 111.Supplement C (2017), pp. 298 -311. ISSN: 0301-4215. DOI: https: // doi .org/10 .1016/j . enpol . 2017 .09 .039. URL: http://www . sciencedirect . com/science/ article/pii/S0301421517305992.

[7] Eskom. Revenue Application FY2018/19. Tech. rep. Johannesburg: Eskom, 2017.

[8] X. Hu et al. "Technological Developments in Batteries: A Survey of Principal Roles, Types, and Management Needs". In: IEEE Power and Energy Magazine 15.5 (2017), pp. 20-31. ISSN: 1540-7977. DOI: 10.1109/MPE. 2017.2708812.

[9] Nicholas DiOrio, Aron Dobos, and Steven Janzou. Economic Analysis Case Studies of Battery Energy Storage with SAM. Tech. rep. Golden, CO: National Renewable Energy Laboratory, 2015.

[10] Eskom. Integrated Report 2015. Tech. rep. Johannesburg: Eskom, 2015.

[11] Eskom. Compact fluorescent lamp rollout. [Online] Accessed: 2017-04-20. 2017. URL: http://www. eskom. co.za/sites/idm/Residential/Pages/CFLRollout.aspx.

[12] Kevin C. van Blommestein and Tugrul U. Daim. "Residential energy efficient device adoption in South Africa". In: Sustainable Energy Technologies and Assessments 1 (2013), pp. 13-27. DOI: 10.1016/j .seta. 2012.12.001. URL: http://linkinghub.elsevier.com/retrieve/pii/S2213138812000033.

[13] Hammed Amusa, Kafayat Amusa, and Ramos Mabugu. "Aggregate demand for electricity in South Africa: An analysis using the bounds testing approach to cointegration". In: Energy Policy 37.10 (2009), pp. 41674175. DOI: 10.1016/j.enpol.2009.05.016. URL: http://linkinghub.elsevier.com/retrieve/pii/ S0301421509003346.

[14] Roula Inglesi. "Aggregate electricity demand in South Africa: Conditional forecasts to 2030". In: Applied Energy 87.1 (2010), pp. 197-204. DOI: 10.1016/j.apenergy .2009.08.017. URL: http://linkinghub . elsevier.com/retrieve/pii/S0306261909003493.

[15] Alix Clark. "Demand-side management investment in South Africa: barriers and possible solutions for new power sector contexts". In: Energy for Sustainable Development 4.4 (2000), pp. 27-35. URL: http: //www.sciencedirect.com/science/article/pii/S0973082608602616.

[16] C. Lombard, E. H. Mathews, and M. Kleingeld. "Demand-Side Management through thermal efficiency in South African houses". In: Energy and buildings 29.3 (1999), pp. 229-239. URL: http : // www . sciencedirect.com/science/article/pii/S0378778898000644. 
[17] R. Rankin and P. G. Rousseau. "Demand side management in South Africa at industrial residence water heating systems using in line water heating methodology". In: Energy Conversion and Management 49.1 (2008), pp. 62-74. DOI: 10.1016/j.enconman.2007.05.022. URL: http://linkinghub.elsevier.com/ retrieve/pii/S0196890407001574.

[18] R. Inglesi-Lotz. "The evolution of price elasticity of electricity demand in South Africa: A Kalman filter application". In: Energy Policy 39.6 (2011), pp. 3690-3696. DOI: 10.1016/j .enpol.2011.03.078. URL: http://linkinghub.elsevier.com/retrieve/pii/S0301421511002758.

[19] STATSSA. Poverty trends in South Africa: An examination of absolute poverty between 2006 and 2015. Tech. rep. Pretoria: Statistics South Africa, 2017.

[20] G. M. Gilbert, D. E. Bouchard, and A. Y. Chikhani. "A comparison of load flow analysis using DistFlow, Gauss-Seidel, and optimal load flow algorithms". In: IEEE Canadian Conference on Electrical and Computer Engineering. Vol. 2. Cat. No.98TH8341. 1998, pp. 850-853.

[21] C.G. Monyei et al. "Examining energy sufficiency and energy mobility in the global south through the energy justice framework". In: Energy Policy 119 (2018), pp. 68 -76. ISSN: 0301-4215. DoI: https://doi . org/10.1016/j.enpol.2018.04.026. URL: http://www.sciencedirect.com/science/article/pii/ S030142151830243X.

[22] GNESD. South African Electrification Programme. [Online] Accessed: 2017-10-15. 2017. URL: http: // energy-access.gnesd.org/cases/22-south-african-electrification-programme.html.

[23] DME. Free Basic Alternative Energy Policy (Households Energy Support programme). [online] Accessed: 2017-10-01. 2007. URL: http : //www . nersa . org · za/Admin/Document/Editor/file/Electricity/ Legislation/Policies/Free\%20Basic\%20Electricity\%20Policy.pdf.

[24] C.G. Monyei, A.O. Adewumi, and K.E.H. Jenkins. "Energy (in)justice in off-grid rural electrification policy: South Africa in focus". In: Energy Research and Social Science, in Press (2018). ISSN: 2214-6296.

[25] Benjamin K. Sovacool et al. "Vulnerability and resistance in the United Kingdom's smart meter transition". In: Energy Policy 109.Supplement C (2017), pp. 767 -781. ISSN: 0301-4215. DoI: https : //doi . org/10.1016/j.enpol.2017.07.037. URL: http://www.sciencedirect.com/science/article/pii/ S0301421517304688.

[26] News24. Eskom may pass on new tax burden. [Online] Accessed: 2017-11-14. 2013. URL: https: //www . news24.com/Archives/City-Press/Eskom-may-pass-on-new-tax-burden-20150430.

[27] Melanie Gosling. Eskom will just pass tax on to consumers. [Online] Accessed: 2017-11-14. 2011. URL: https : //www . iol . co .za/business - report/economy / eskom - will - just-pass - tax - on - to consumers-1162085.

[28] eePublishers. Eskom defers transmission development plan and N-1 compliance. [Online] Accessed: $2017-$ 11-15. 2014. URL: http://www.ee.co.za/article/eskom-defers-transmission-development-plann-1-compliance.html. 
[29] Kuangyuan Zhang. Target versus price: improving energy efficiency of industrial enterprises in China. 2012. URL: http://www.usaee.org/usaee2014/submissions/Presentations/TargetPrice_IAEE2014. pdf.

[30] Chukwuma Leonard Azimoh et al. "Replicability and scalability of mini-grid solution to rural electrification programs in sub-Saharan Africa". en. In: Renewable Energy 106 (June 2017), pp. 222-231. ISSN: 09601481. DOI: 10.1016/j.renene.2017.01.017. URL: http://linkinghub.elsevier.com/retrieve/ pii/S0960148117300174 (visited on 10/15/2017). 


\section{List of Tables}

Table 1: 2021-2024 Planned Power Plant Decommissioning (Eskom 2015b)

\begin{tabular}{ccccccc}
\hline & \multicolumn{2}{c}{ Camden } & \multicolumn{2}{c}{ Hendrina } & \multicolumn{2}{c}{ Arnot } \\
Year & Unit & MW & Unit & MW & Unit & MW \\
\hline 2021 & 6 & -160 & 4 & -190 & & \\
\hline 2022 & 7 & -170 & 3 & -190 & & \\
& 8 & -180 & 5 & -180 & & \\
\hline 2023 & 5 & -180 & 2 & -190 & 3 & -380 \\
& 4 & -185 & & & 2 & -380 \\
\hline & 3 & -185 & 1 & -190 & 1 & -376 \\
2024 & 2 & -190 & & & & \\
& 1 & -190 & & & & \\
\hline
\end{tabular}

Table 2: 2017-2020 Planned Power Plant Capacity Increment (Eskom 2015b)

\begin{tabular}{|c|c|c|c|c|c|c|c|c|c|c|c|c|}
\hline \multirow[b]{2}{*}{ Year } & \multicolumn{2}{|c|}{ Medupi } & \multicolumn{2}{|c|}{ Kusile } & \multicolumn{2}{|c|}{ Ingula } & \multicolumn{3}{|c|}{ New coal } & \multicolumn{3}{|c|}{ O \& C CGT } \\
\hline & Unit & MW & Unit & MW & Unit & MW & Unit & Name & MW & Unit & Name & MW \\
\hline \multirow[t]{2}{*}{2017} & 3 & 738 & 2 & 738 & 4 & 333 & & & & & & \\
\hline & 4 & 738 & & & & & & & & & & \\
\hline \multirow[t]{2}{*}{2018} & 5 & 738 & 3 & 738 & & & & & & & & \\
\hline & & & 3 & 738 & & & & & & & & \\
\hline \multirow[t]{2}{*}{2019} & 6 & 738 & 5 & 738 & & & 1 & Coal IPP1 & 200 & 3 & Dedisa & 237 \\
\hline & & & & & & & 2 & Coal IPP1 & 200 & & & \\
\hline \multirow[t]{2}{*}{2020} & & & 6 & 738 & & & 1 & Coal IPP3 & 200 & 4 & Dedisa & 237 \\
\hline & & & & & & & 2 & Coal IPP3 & 200 & & & \\
\hline
\end{tabular}

IPP - Independent Power Producer

Table 3: 2021-2024 Planned Power Plant Capacity Increment (Eskom 2015b)

\begin{tabular}{|c|c|c|c|c|c|c|c|c|c|c|c|c|}
\hline \multirow[b]{2}{*}{ Year } & \multicolumn{3}{|c|}{ Nuclear } & \multicolumn{3}{|c|}{ Newcoal } & \multicolumn{3}{|c|}{$\mathrm{O} \& \mathrm{C}$ CGT } & \multicolumn{3}{|c|}{ Hydro import } \\
\hline & Unit & Name & MW & Unit & Name & MW & Unit & Name & MW & Unit & Name & MW \\
\hline 2021 & & & & & & & 5 & Dedisa & 237 & & & \\
\hline \multirow{4}{*}{2022} & & & & 1 & Coal IPP2 & 250 & 6 & Dedisa & 269 & 1 & Maputo & 570 \\
\hline & & & & 2 & Coal IPP2 & 250 & 7 & Dedisa & 269 & 2 & Maputo & 570 \\
\hline & & & & 1 & Coal IPP4 & 250 & 8 & Dedisa & 269 & & & \\
\hline & & & & 2 & Coal IPP4 & 250 & & Dedisa & & & & \\
\hline \multirow{3}{*}{2023} & 1 & Thyspunt & 1600 & 3 & Coal IPP2 & 250 & & & & 3 & Maputo & 570 \\
\hline & & & & 3 & Coal IPP4 & 250 & & & & 4 & Maputo & 570 \\
\hline & & & & 4 & Coal IPP4 & 250 & & & & & & \\
\hline 2024 & 2 & Thyspunt & 1600 & 4 & Coal IPP2 & 250 & & & & 5 & Maputo & 283 \\
\hline
\end{tabular}


Table 8: Considered power plant description.

\begin{tabular}{cccc}
\hline Generation plant number & Name & Type & Capacity (MW) \\
\hline 1 & Arnot & Coal & 2352 \\
\hline 2 & Duvha & Coal & 3600 \\
\hline 3 & Hendrina & Coal & 4116 \\
\hline 4 & Kendal & Coal & 1940 \\
\hline 5 & Koeberg & Nuclear & 3000 \\
\hline 6 & Kriel & Coal & 3708 \\
\hline 7 & Lethabo & Coal & 4110 \\
\hline 8 & Majuba & Coal & 3990 \\
\hline 9 & Matimba & Coal & 3600 \\
\hline 10 & Matla & Coal & 3654 \\
\hline 11 & Tutuka & Coal & 1510 \\
\hline 12 & Camden & Coal & 1200 \\
\hline 13 & Grootvlei & Coal & 940 \\
\hline 14 & Komati & Coal & 4788 \\
\hline 24 & Medupi** & Coal & 4800 \\
\hline 26 & Kusile** & Coal & 1429 \\
\hline 27 & SB1** & Coal & 1429 \\
\hline 28 & SB2 ${ }^{* *}$ & Coal & \\
\hline
\end{tabular}

* - return to service power plants

$* *$ - new builds

SB1/SB2 - simulated builds 1 and 2 are the fictitious power plants randomly used during Scenarios 2 and 3 simulation.

Table 9: Daily DSM load associated statistics for all cases.

\begin{tabular}{|c|c|c|c|c|c|c|}
\hline & \multirow{2}{*}{ Maximum build (MW) } & \multirow{2}{*}{ Capacity utilization (\%) } & \multicolumn{4}{|c|}{ DSM cost $(\mathrm{x} 10000000)$} \\
\hline & & & TOU cost (ZAR) & DP1 cost (ZAR) & $\mathrm{DP} 2$ cost (ZAR) & DP3 cost (ZAR) \\
\hline Case 1 & 495.01 & 33.34 & 2.2093 & 1.648 & 1.9131 & 2.3183 \\
\hline Case 2 & 173.48 & 95.14 & 2.0669 & 2.0181 & 2.0267 & 2.0084 \\
\hline Case 3 & 363.84 & 45.36 & 2.1616 & 1.7726 & 1.9742 & 2.2515 \\
\hline
\end{tabular}

Table 10: Daily cumulative losses (MW) for all scenarios and cases.

\begin{tabular}{cccc}
\hline & Scenario 1 & Scenario 2 & Scenario 3 \\
\hline Case 1 & 86512 & 84321 & 84029 \\
\hline Case 2 & 86438 & 84150 & 83858 \\
\hline Case 3 & 86498 & 84305 & 84014 \\
\hline
\end{tabular}




\section{List of Figures}

1

2

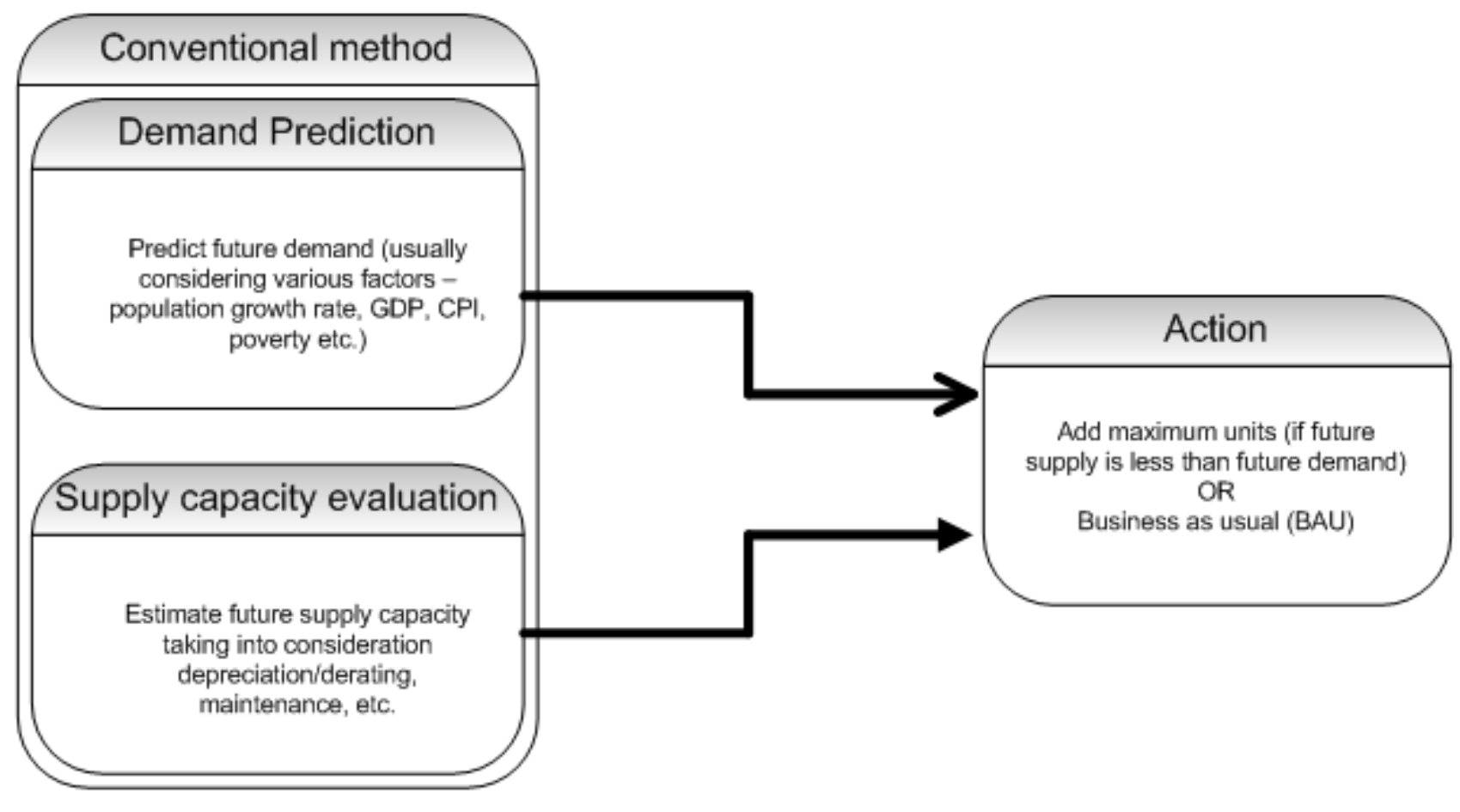

Figure 1: Eskom's conventional electricity expansion model (authors own compilation). 


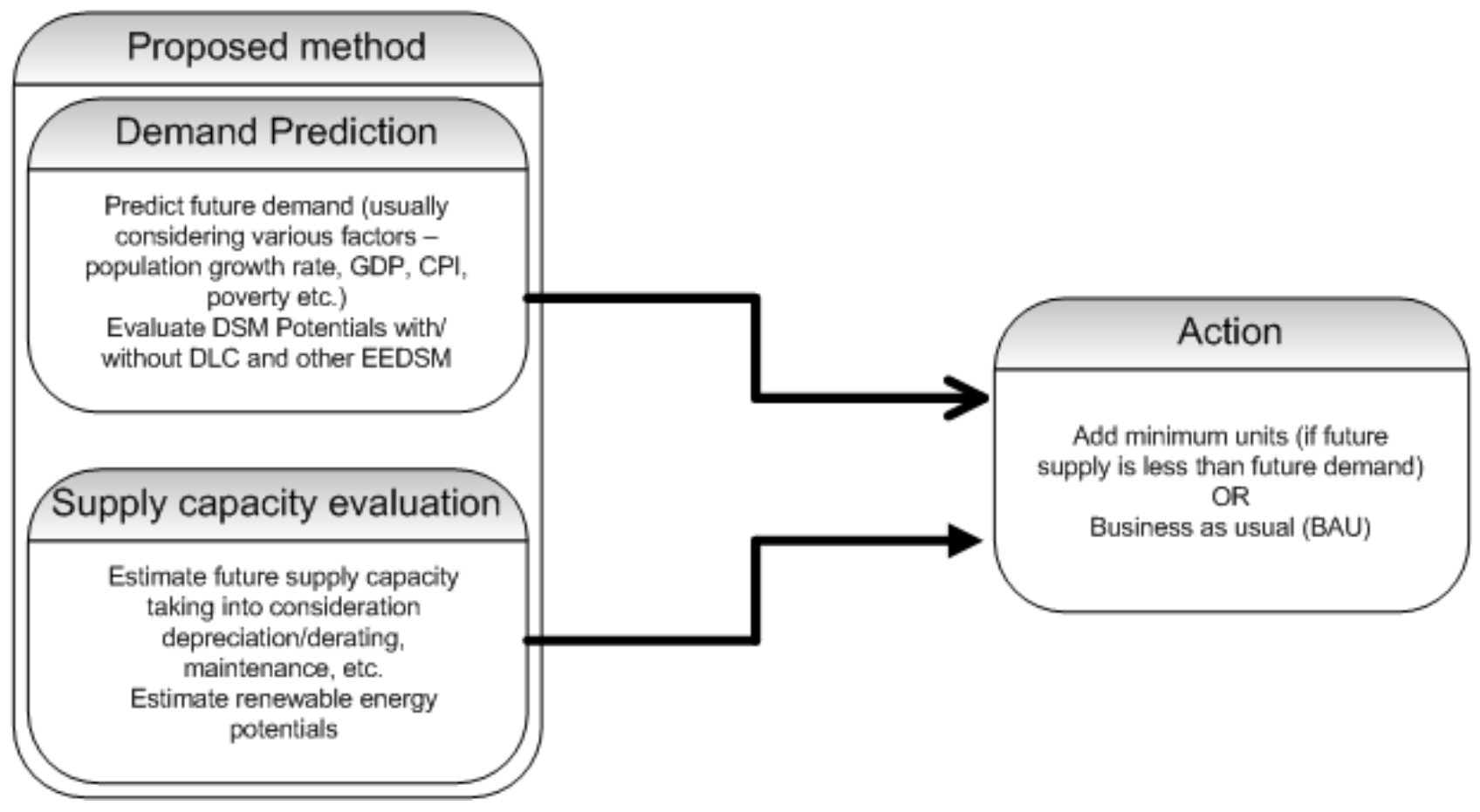

Figure 2: Integrated electricity expansion model (IEEM) (authors own compilation). 


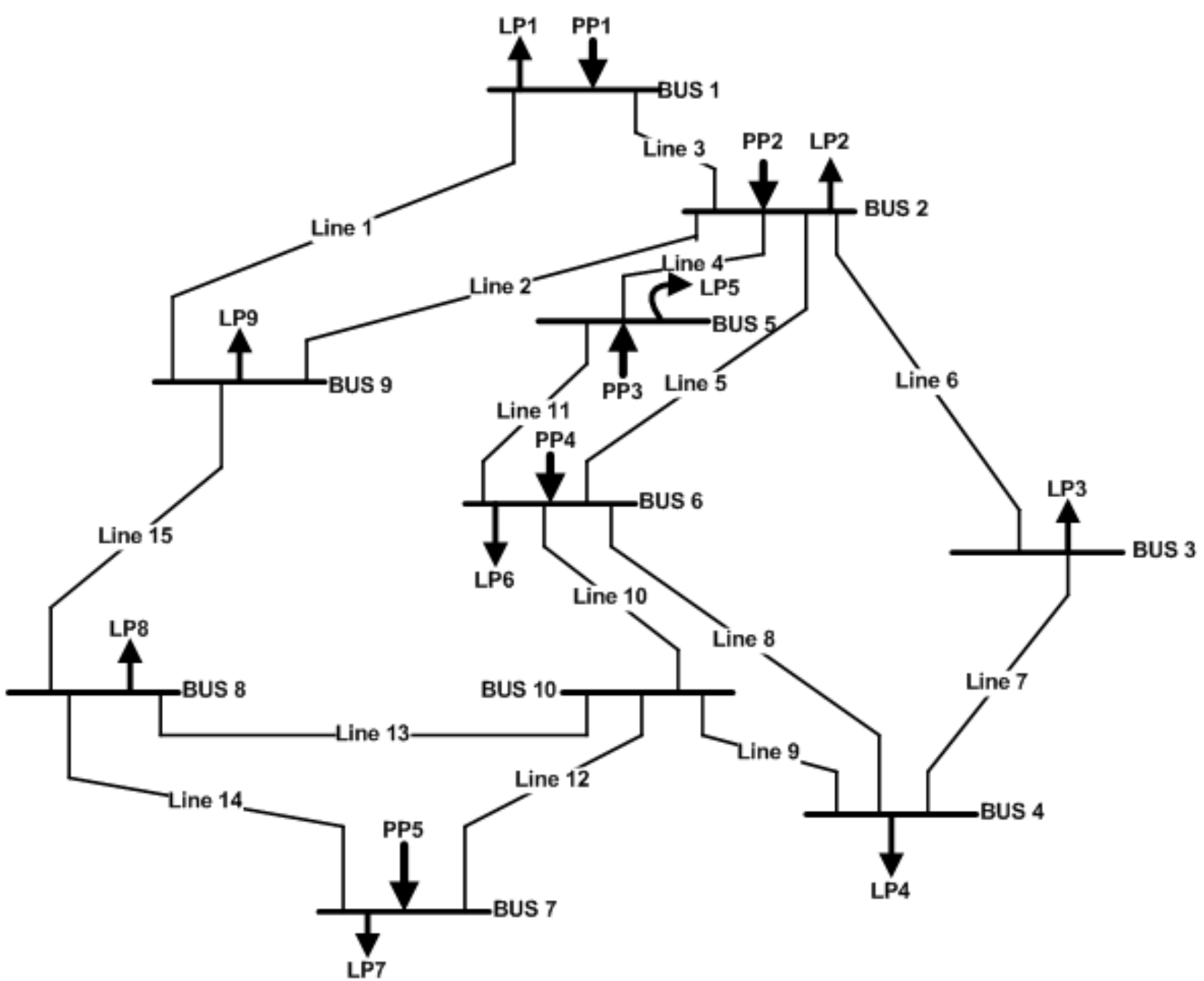

Figure 3: Model electricity network for South Africa (authors own compilation).

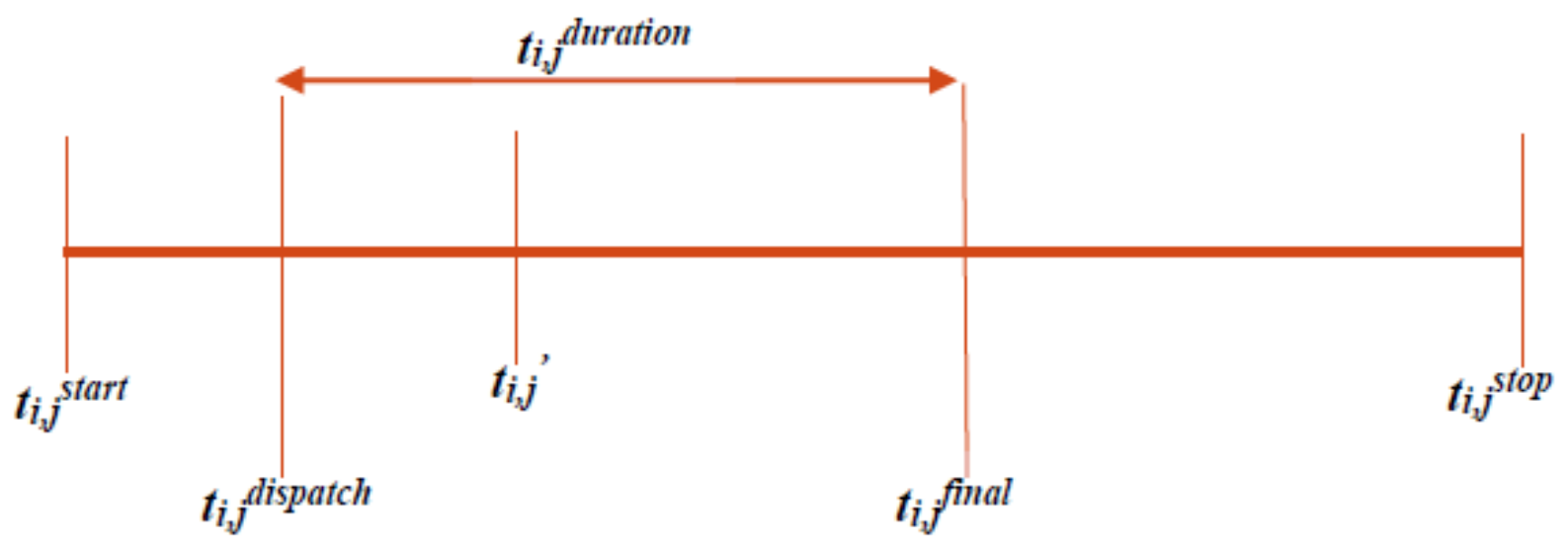

$w_{i}$

Figure 4: Dispatch time profile for DSM loads (authors own compilation). 


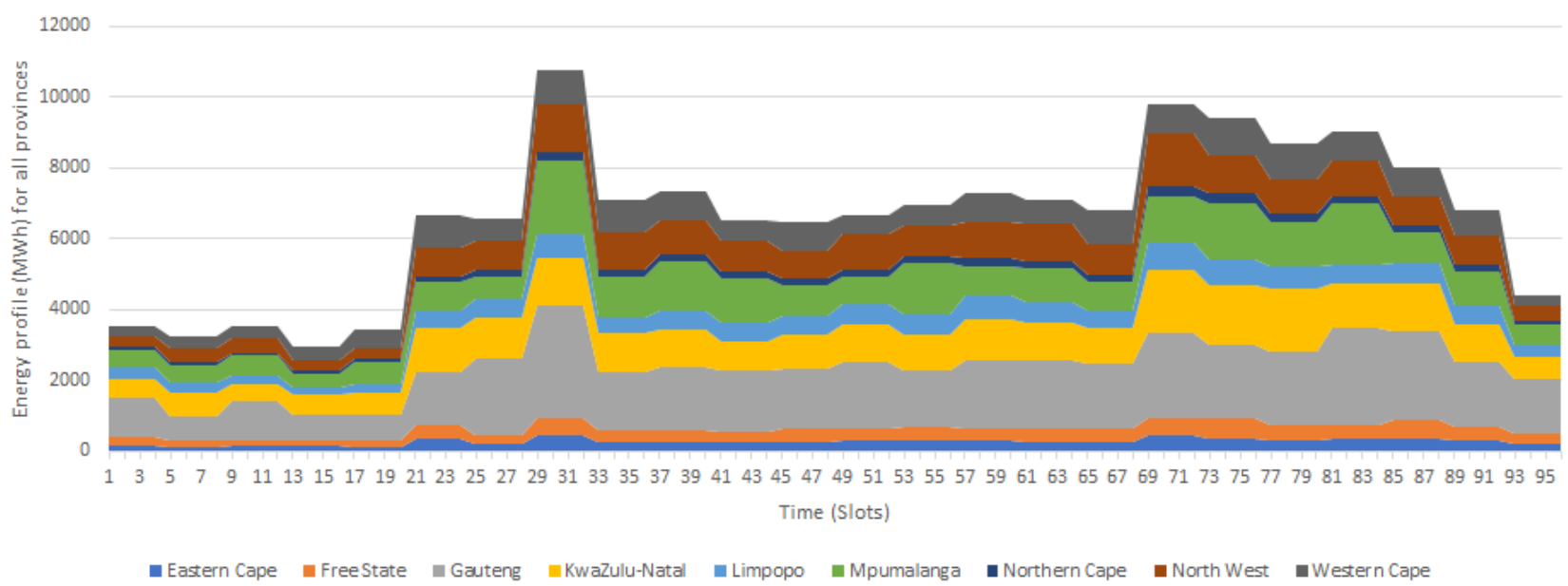

A slot is a 15 minutes interval. The start time is taken to be 00:00 (midnight/slot 1).

Figure 5: Base load dispatch profile for all provinces (authors own compilation).

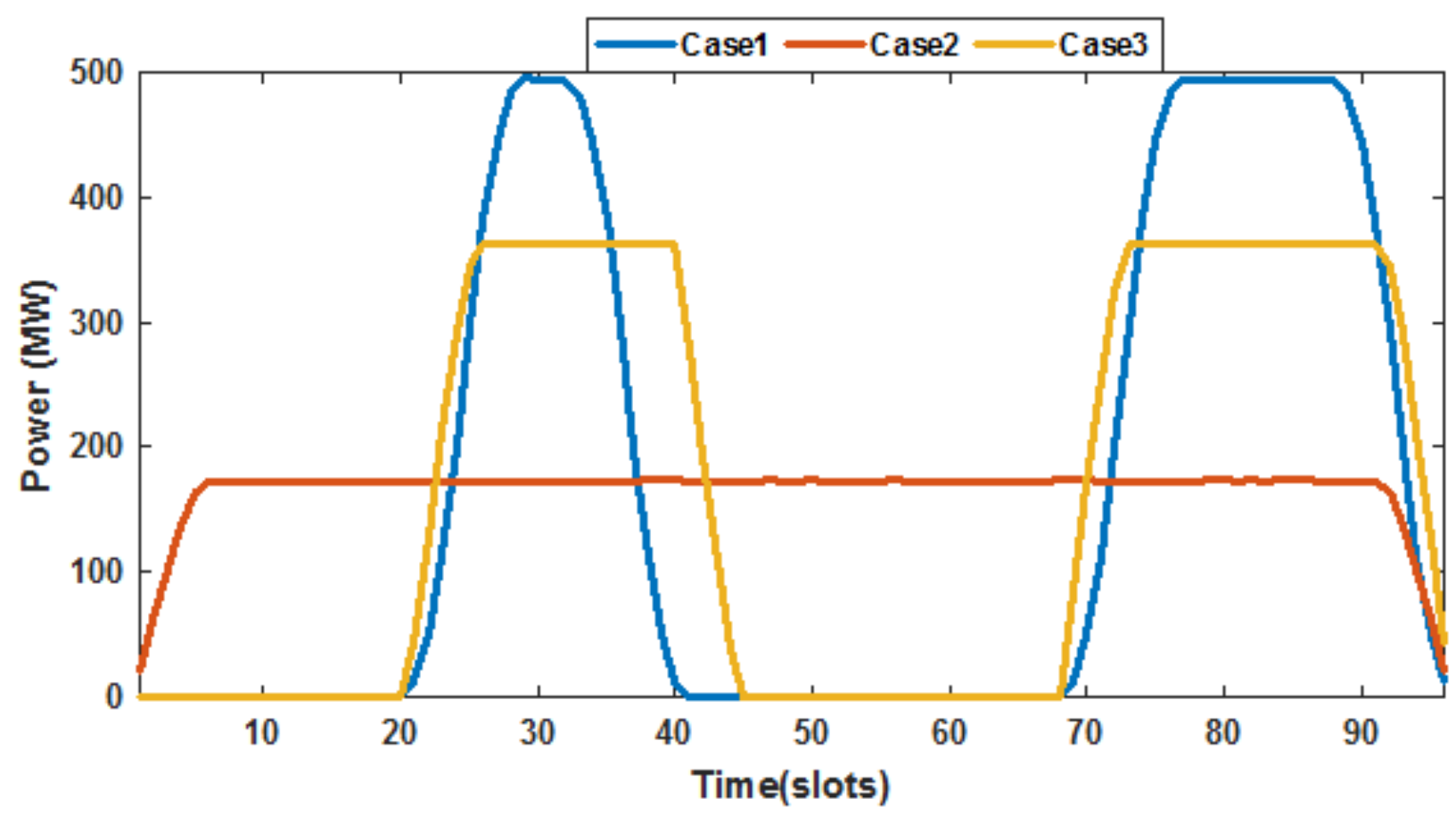

A slot is a 15 minutes interval. The start time is taken to be 00:00 (midnight/slot 1).

Figure 6: Cumulative DSM load profile for all Cases (authors own compilation). 


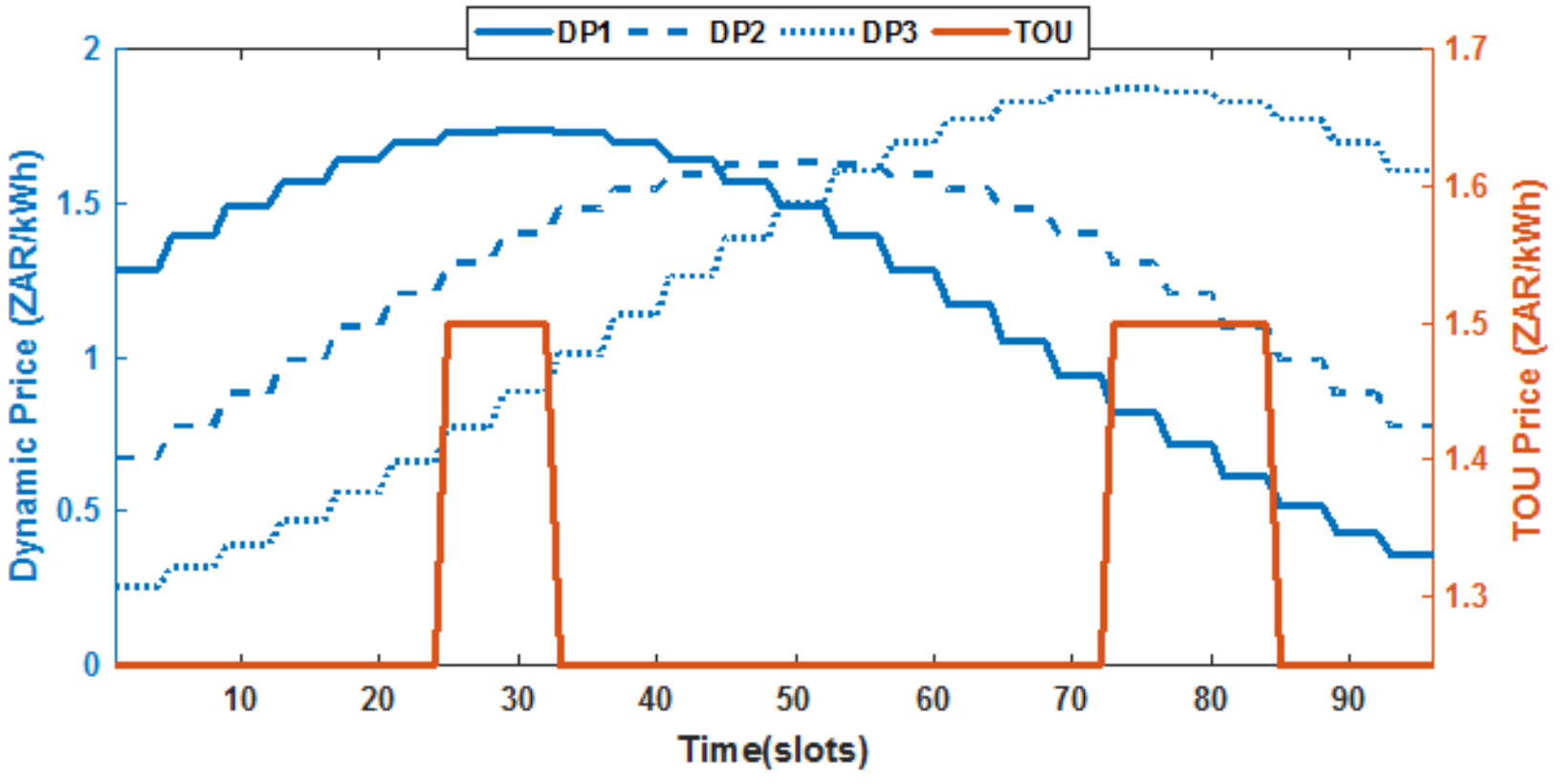

A slot is a 15 minutes interval. The start time is taken to be 00:00 (midnight/slot 1).

Figure 7: Pricing schemes adopted.

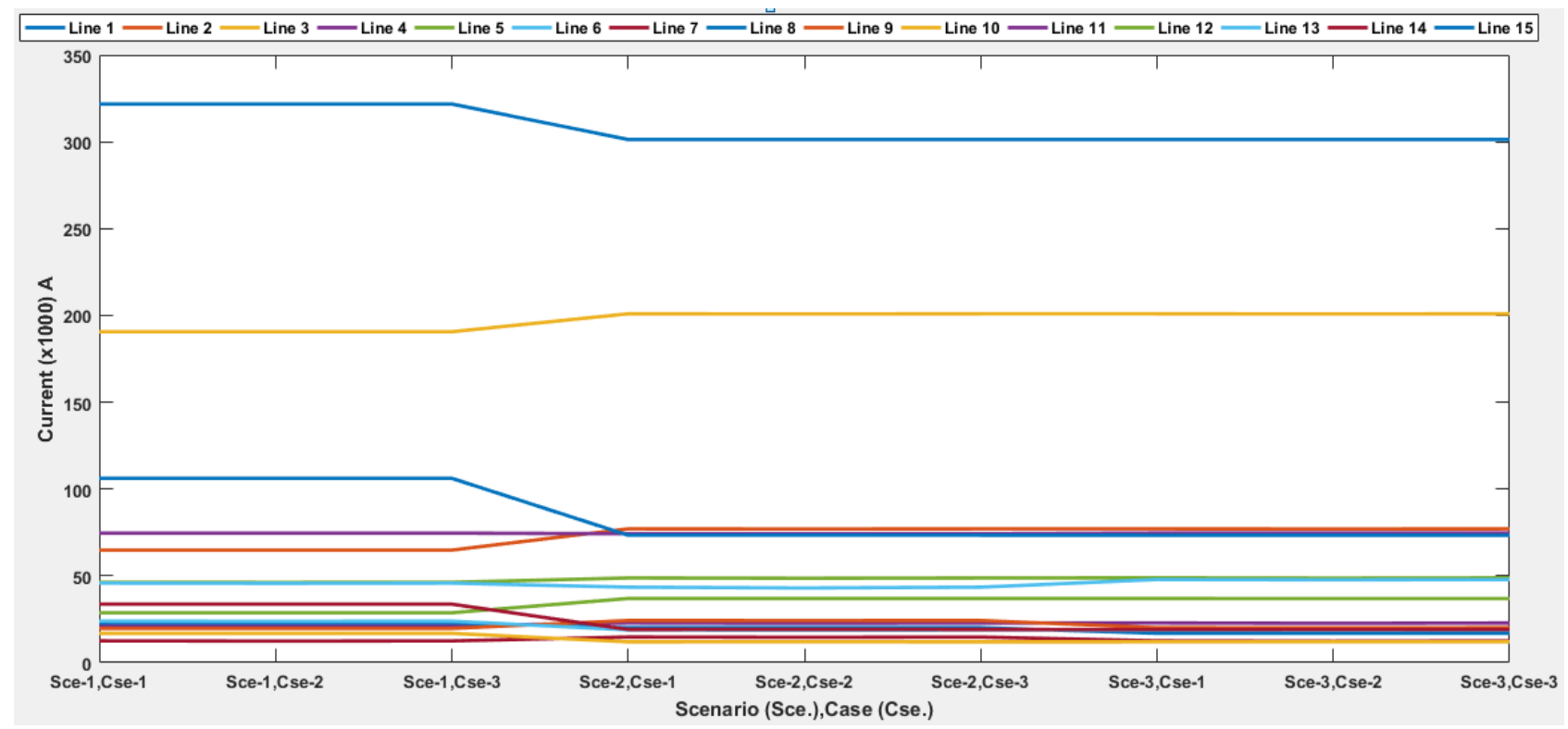

Figure 8: Daily current evacuated per line (in kA). 


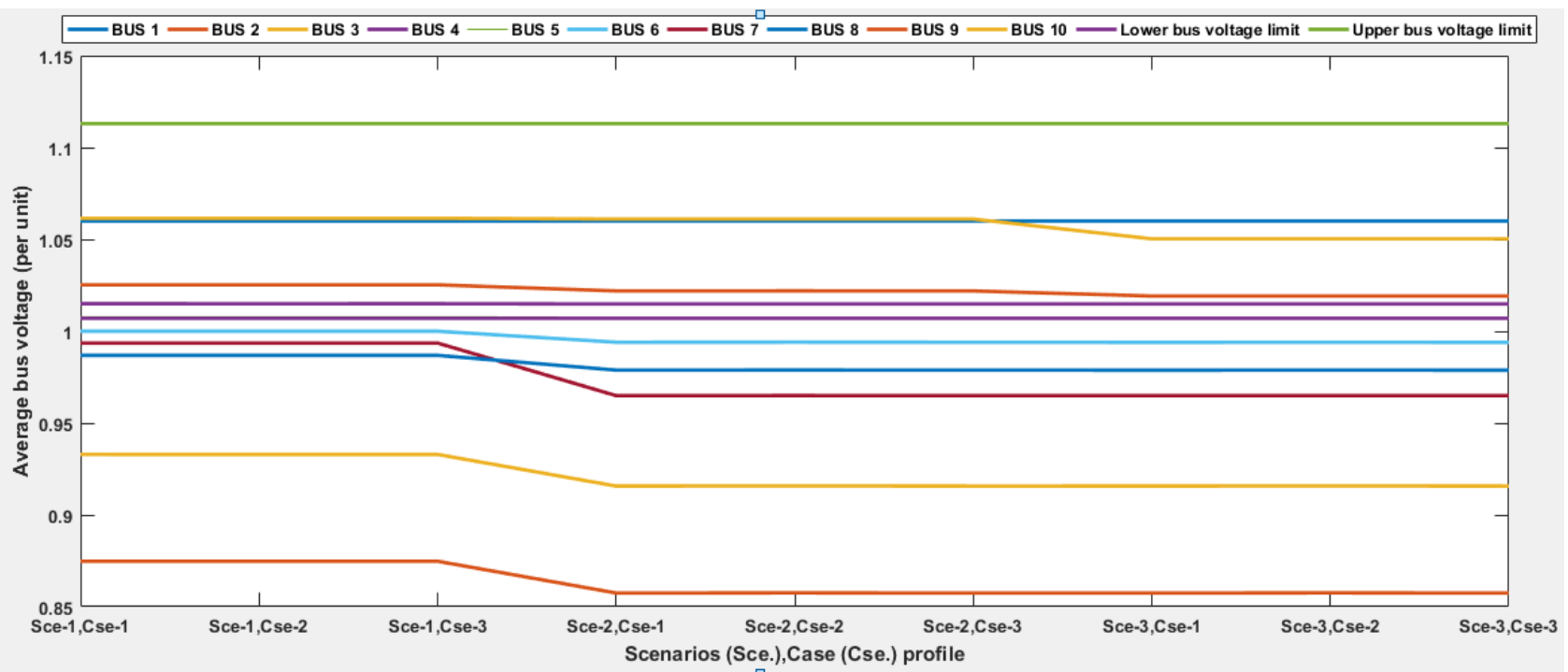

Figure 9: Daily average bus voltage (in per unit) profile. 
LaTeX Source Files
Click here to download LaTeX Source Files: JEPO_R1.zip

LaTeX Source Files
Click here to download LaTeX Source Files: JEPO_R1.zip

Click here to download LaTeX Source Files: JEPO_R1:zip

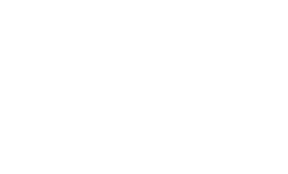

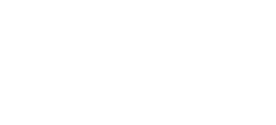

(1)

(1)

$\sqrt{2}$

